\title{
Avaliação retrorrefletiva de pintura de demarcação horizontal: peculiaridades e considerações sobre a norma e os requisitos mínimos nacionais
}

\author{
Lucio Salles de Salles ${ }^{1}$, Deividi da Silva Pereira² ${ }^{2}$ Daniel Luiz Krachefski Teixeira ${ }^{3}$ e Luciano Pivoto Specht ${ }^{4}$
}

\begin{abstract}
Resumo: A retrorrefletividade das pinturas de demarcações horizontais permite a visibilidade da sinalização viária durante a noite, impactando diretamente a segurança da via. O Brasil emprega normas e requisitos mínimos internacionas que foram parcialmente adaptados para as condições do país. De maneira geral, tais adaptações reduziram os níveis de segurança exigidos por estes importantes dispositivos, fato que pode acarretar prejuízos à condição de segurança e conforto. A partir da avaliação ao longo de dois anos de três segmentos experimentais, um rodoviário e dois urbanos, com diferentes tipos de demarcações e materiais, buscou-se fazer uma análise crítica da pertinência da forma de avaliação normativa no Brasil, bem como estudar o impacto da chuva, do acúmulo de sujeira e da geometria dos retrorrefletômetros sobre o desempenho da sinalização horizontal. Como esperado, demarcações empregando material termoplástico apresentaram um desempenho superior àquelas com tinta acrílica. O efeito abrasivo da interação pneu-pavimento desgasta tais dispositivos, reduzindo o número de elementos retrorrefletivos (microesferas); entretanto, a combinação tráfego mais precipitação mostrou-se positiva por permitir a limpeza "natural" da sinalização. Para o trecho urbano, o efeito da sujeira foi tão prejudicial quanto à abrasão causada por veículos pesados. A análise da retrorrefletividade, obtida com diferentes geometrias, perante limites mínimos nacionais e internacionais, demonstrou que os índices mínimos de retrorrefletividade aplicados no Brasil são pouco exigentes, merecendo, portanto, serem rediscutidos para melhor atender aos quesitos de segurança viária.
\end{abstract}

Palavras-chave: demarcação viária; retrorrefletividade; requisitos mínimos; retrorrefletômetro.

\begin{abstract}
Horizontal markings retroreflectivity allows road night visibility, which directly impacts road safety. Brazil employs international standards and minimum retroreflectivity requirements that were partially adapted to the country conditions. In general, such adjustments reduced the security levels of these devices damaging road safety and comfort. From the evaluation of three experimental sections (one highway and two urban avenues) with different markings and materials, over two years, the Brazilian standard procedure was critically analyzed. Also, the impact of rainfall, dirt and retroreflectometer geometry on the horizontal markings performance was addressed. As expected, thermoplastic markings outperformed those with acrylic paint. The abrasive effect of the tire-pavement interaction outwears the markings, reducing the number of retroreflective elements (glass beads); however, the combination of traffic plus rainfall was positive for allowing a "natural" marking cleaning. For the urban section, the effect of dirt was as damaging as the abrasion caused by heavy vehicles. The analysis of retroreflectivity, obtained with different geometries, regarding national and international thresholds, showed that the retroreflectivity minimum levels applied in Brazil are inefficient, deserving, therefore, to be discussed to better serve road safety criteria.
\end{abstract}

Keywords: road markings; retroreflectivity; minimum requirements; retroreflectometer.

\section{INTRODUÇÃO}

O Anuário Estatístico de Acidentes de Trânsito em Rodovias Federais apontou, em 2010, que 69\% dos acidentes ocorreram no período diurno, entre às 6h e 19h. É natural entender esta concentração de acidentes como consequência da grande demanda por deslocamentos neste período. No entanto, segundo o mesmo documento apresentado em DNIT (2010), nas rodovias brasileiras, das 7.073 mortes registradas em rodovias federais, 62,6\% ocorreram no período noturno.

\footnotetext{
${ }^{1}$ Lucio Salles de Salles, Departamento de Engenharia de Transportes, Escola Politécnica da Universidade de São Paulo. (lucio.salles@usp.br) 2 Deividi da Silva Pereira, Departamento de Engenharia de Transportes, Universidade Federal de Santa Maria, RS. (dsp@ufsm.br)

${ }_{3}$ Daniel Luiz Krachefski Teixeira, Departamento de Engenharia de Transportes, Universidade Federal de Santa Maria, RS.

(Iktdaniel@hotmail.com)

${ }^{4}$ Luciano Pivoto Specht, Departamento de Engenharia de Transportes,

Universidade Federal de Santa Maria, RS. (luspecht@gmail.com)

Manuscrito recebido em 05/02/2015 e aprovado para publicação em 28/06/2015.

Este artigo é parte de TRANSPORTES v. 23, n. 3, 2015. ISSN: 2237-1346 (online). DOI: 10.14295/transportes.v23i3.886.
}

Ainda em 2010, as estatísticas demonstraram que nas rodovias federais houve 78,3 mortes por mil acidentes em períodos noturnos, taxa 3,7 vezes superior à taxa de mortalidade em acidentes diurnos (21 mortes por mil acidentes). Esta desconfortável realidade, por si só, justificaria a intensificação de estudos técnicos com o intuito de melhorar as condições de segurança viária nos períodos noturnos.

Estima-se em 2,8 bilhões o dispêndio total do Brasil com acidentes fatais em períodos noturnos nas rodovias federeias em 2010, se considerado o custo médio por morte de R\$ 631.996,20 apontado em CNT (2012).

Durante o período noturno em rodovias, o único meio de comunicação entre o condutor e a via são as pinturas de demarcação horizontais e as placas de sinalização vertical; Lee e Donnell (2007) observaram grandes mudanças no comportamento de motoristas durante a noite em relação ao período diurno devido a alterações no campo de visão do condutor.

Para que a sinalização seja perfeitamente visível à noite, os elementos que a compõe devem retornar a luz originária dos faróis dos veículos para o campo de visão do motorista; a este fenômeno dá-se o nome de retrorrefletividade. 
Diversos estudos comprovaram que maiores valores de retrorrefletividade da sinalização rodoviária aumentam a visibilidade dos motoristas e a capacidade de percepção e interpretação de distâncias durante a noite. (Graham e King, 1991; Miglletz et al., 1999; Parker e Meja, 2003; Zwahlen e Schnell, 1999). Horberry et al. (2006) evidenciaram uma dirigibilidade mais adequada por parte dos motoristas quando expostos a demarcações com alta qualidade retrorrefletiva.

Donnell et al. (2009) e Smadi et al. (2008) não encontraram relações concretas entre a retrorrefletividade e o número de acidentes. Bahar et al. (2004), inclusive, constataram um leve aumento no número de acidentes quando a via passava por uma nova pintura aumentando a retrorrefletividade das demarcações. Embora contraintuitivos, os autores explicam que os resultados podem ser influenciados pelo comportamento do motorista, que em uma rodovia melhor sinalizada, torna-se mais confiante, cometendo imprudências e trafegando com velocidades mais altas.

Entretanto, a despeito dos estudos citados anteriormente, o trabalho recente de Carlson et al. (2013) aferiu, claramente, reduções no número de acidentes noturnos com o aumento da retrorrefletividade de bordo e de eixo.

Em recente pesquisa rodoviária, a Confederação Nacional dos Transportes (CNT, 2014) apurou que a malha rodoviária brasileira administrada pela gestão pública apresenta 57\% de sua extensão com pinturas de demarcações viárias desgastadas ou inexistentes, incompatíveis, portanto, com a perfeita capacidade de retrorrefletir a luz proveniente dos faróis dos veículos durante o período noturno.

A pesquisa ora apresentada traz a avaliação da retrorrefletividade ao longo de dois anos de três trechos distintos, dois urbanos e um rodoviário, com materiais e demarcações diferentes. A partir da sistêmica avaliação da retrorrefletividade dos trechos experimentais, buscou-se, fundamentalmente, verificar a adequação da norma nacional na avaliação deste importante índice relacionado com a segurança viária. Também objetivou-se correlacionar os parâmetros últimos de retrorrefletividade apontados no país e no exterior, com a geometria especificada na norma nacional (15m), verificando a pertinência destes valores em relação às condições de segurança impostas pelas agências internacionais.

Através das observações de campo, ainda foi possível inferir a respeito da influência de fatores externos tais como chuva, sujeira e serviços de conservação da demarcação na qualidade de retrorrefletividade da sinalização horizontal. Por fim, ao confrontar os resultados de dois equipamentos com geometrias de 30 e $15 \mathrm{~m}$, foi possível determinar um fator de correlação entre estas geometrias que permite uma comparação direta entre a norma nacional e americana/europeia, bem como a avaliação do desempenho dos trechos analisados perante requisitos mínimos regulamentados por órgãos nacionais e internacionais.

\section{REVISÃO BIBLIOGRÁFICA}

O elemento que confere retrorrefletividade às pinturas de demarcação são as microesferas de vidro; elas apresentam diversos diâmetros e podem ser pré-misturadas (premix) à tinta e ao termoplástico (intermix) e/ou aspergidas no momento da aplicação da demarcação (drop-on).
Gibbons e Hankey (2007) mostraram que materiais termoplásticos apresentam um desempenho retrorrefletivo superior às tintas acrílicas, mesmo aquelas com microesferas de grande e médio diâmetro. No âmbito nacional, Schwab (1999) comparou diversos materiais de demarcação e concluiu que os elastoplásticos e os termoplásticos também apresentaram durabilidade bastante superior quando comparados às tintas acrílicas.

De maneira geral, Donnell et al. (2009) afirmam que a retrorrefletividade decai com o tempo e de forma diferente conforme o tipo de material, mas sempre em função da perda do material retrorrefletivo (microesferas) devido à ação abrasiva do tráfego.

A retrorrefletividade é medida através de equipamentos chamados retrorrefletômetros. Estes emitem sobre a demarcação uma luz com determinado ângulo de incidência e captam o quanto dessa luz retorna em uma câmara fechada. Os resultados são valores numéricos do coeficiente de luminância retrorrefletida $\left(R_{L}\right)$ que é medido em milicandelas por metro quadrado por lux (mcd. $\left.\mathrm{m}^{-2} \cdot \mathrm{lx}^{-1}\right)$.

Existem diversos tipos de retrorrefletômetros que diferem-se, basicamente, por sua geometria angular (12, 15 ou $30 \mathrm{~m}$ ). Por exemplo, os retrorrefletômetros com geometria de 30m medem o retorno da luz, simulando 30m de distância entre o motorista/veículo e o ponto da pintura de demarcação viária que retrorrefletiu a luz proveniente dos faróis. Assim, quanto maior a geometria especificada por norma, mais rígida e favorável à segurança viária será a regulamentação.

A regulamentação brasileira, a partir da ABNT, não apresenta valores de retrorrefletividade mínimos que a pintura de demarcação deve oferecer aos usuários. Em suas normas de avaliação, a antiga (ABNT, 2005) e a atual (ABNT, 2013), especificam o emprego de equipamento com geometria de $15 \mathrm{~m}$, cabendo às agências reguladoras e órgãos rodoviários estipularem o limite mínimo de retrorrefletividade.

O Departamento Nacional de Infraestrutura de Transportes (DNIT), em licitações para sinalização no Rio Grande do Sul (DNIT, 2013), seguindo especificações técnicas do Programa BR-LEGAL, exige que a retrorrefletividade das pinturas de demarcação nunca esteja abaixo (mínima residual final) de 80 e $100 \mathrm{mcd}^{-2} \mathrm{~m}^{-2} \cdot \mathrm{lux}^{-1}$ para as cores amarela e branca, respectivamente. Sabe-se que na cor branca, a mais clara do espectro, os valores de retrorrefletividade tendem a ser maiores do que na cor amarela (Zhang, 2009). Já para os valores iniciais, afeitos ao controle tecnológico, os patamares são de 150 e $250 \mathrm{mcd} \cdot \mathrm{m}^{-2} \cdot \mathrm{lux}^{-1}$ para a mesma ordem de cores (amarela/branca).

As concessionárias, a partir das agências reguladoras como a Agência Reguladora de Transporte do Estado de São Paulo (ARTESP, 2014), informam que, nos últimos anos, o valor de referência mínimo residual para as suas concessões passou de 80 para $120 \mathrm{mcd}^{-2} \mathrm{~m}^{-2} \cdot \mathrm{lux}^{-1}$. O mesmo ocorreu com as exigências relativas à qualidade da pintura de demarcação viária contidas nos Programas de Exploração das Rodovias (PER) sob regulação da Agência Nacional de Transportes Terrestres (ANTT, 2014), quando, no final da década de 1990 exigia-se valores mínimos de $80 \mathrm{mcd} \cdot \mathrm{m}^{-2}$.lux ${ }^{-1}$. Com as novas concessões rodoviárias federais, este valor passou para $120 \mathrm{mcd}^{-2} \mathrm{~m}^{-2} \cdot \mathrm{lux}^{-1} \mathrm{e}$ 130mcd. $\mathrm{m}^{-2}$.lux ${ }^{-1}$, respectivamente em 2008 e em 2014. Em 


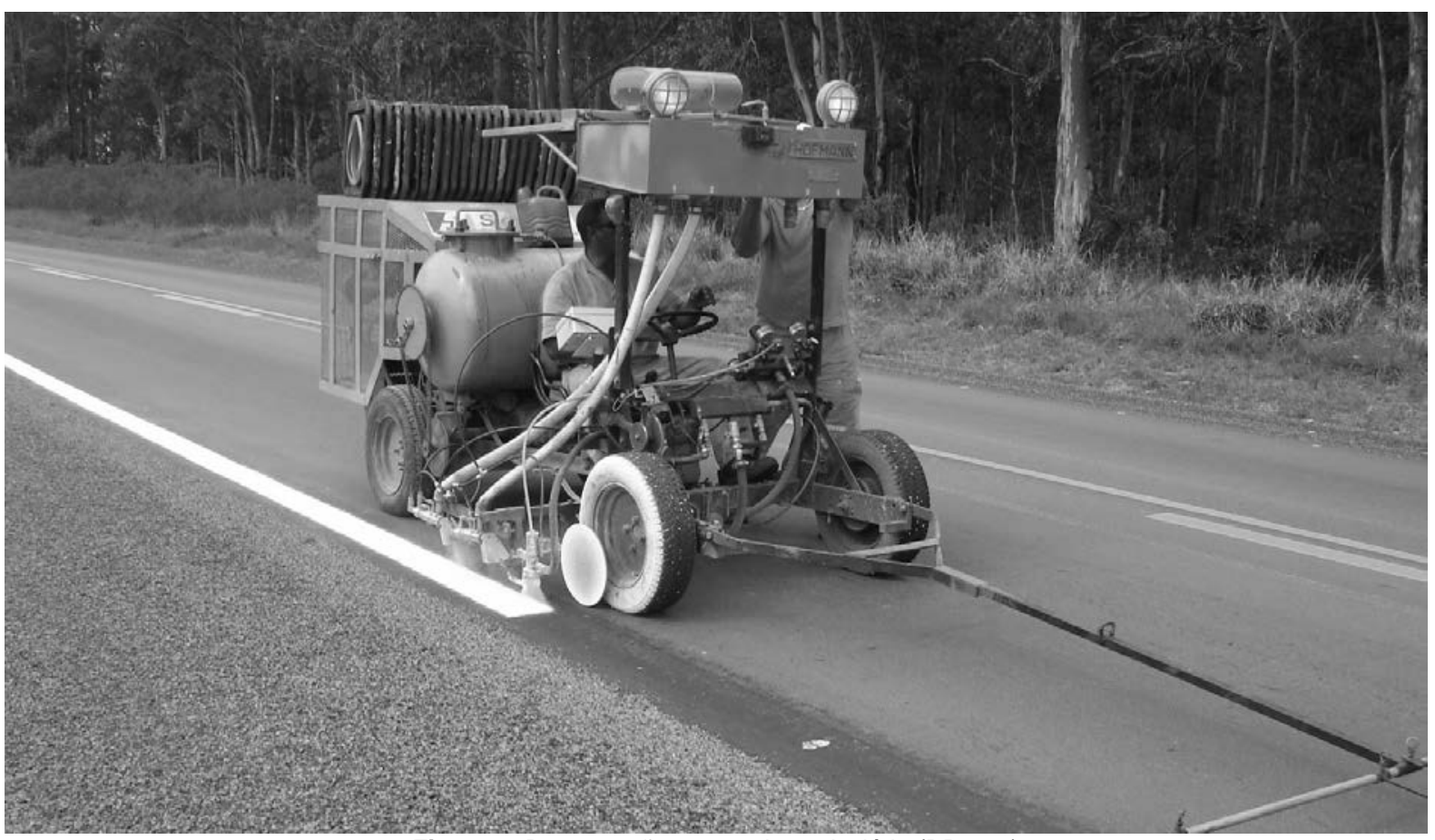

Figura 1. Demarcações no trecho rodoviário (BR-158)

tempo, reitera-se que os valores limites estabelecidos no Brasil referem-se à geometria de $15 \mathrm{~m}$, segundo estabelecido em norma (ABNT, 2013).

Diferentemente da ABNT, a norma americana ASTM (2011) indica para levantamentos de retrorrefletividade um equipamento com geometria de $30 \mathrm{~m}$. Em contrapartida, de maneira análoga ao caso brasileiro, também não possui valores mínimos residuais finais de retrorrefletividade. A Federal Highway Administration (FHWA, 2008) relaciona os índices mínimos de retrorrefletividade para cada coloração e velocidade máxima permitida na via; valores entre 85 e 150 mcd. $\mathrm{m}^{-2}$.lux ${ }^{-1}$ para o bordo (cor branca) e 55 e 100 mcd. $\mathrm{m}^{-2}$. lux ${ }^{-1}$ para o eixo (amarela). As normas europeias regulam um mínimo de $100 \mathrm{mcd}^{-2} \mathrm{~m}^{-2} \cdot \mathrm{lux}^{-1}$ para dias secos e de 35 mcd. $\mathrm{m}^{-2}$. lux ${ }^{-1}$ para dias chuvosos (ECS, 1999).

O principal objetivo de estudos sobre a retrorrefletividade sempre foi a determinação de valores mínimos residuais de referência deste parâmetro capazes de propiciar ao condutor a perfeita percepção visual da pintura de demarcação viária, mesmo sob condições críticas de dirigibilidade (noite e/ou chuva). Gibbons et al. (2013) indicam um mínimo de $150 \mathrm{mcd} . \mathrm{m}^{-2}$.lux ${ }^{-1}$ para manter uma visibilidade adequada em noites chuvosas (situação mais crítica). Deballion et al. (2008) recomendam valores mínimos dentre 40 e $90 \mathrm{mcd}^{\mathrm{m}} \mathrm{m}^{-2}$.lux ${ }^{-1}$ dependendo da velocidade máxima permitida na rodovia. Hummer et al. (2011) sugerem um mínimo de 100 e $65 \mathrm{mcd} . \mathrm{m}^{-2}$. lux ${ }^{-1}$ para a retrorrefletividade de demarcações brancas e amarelas, respectivamente; e informam que a previsão para alcançar esses valores é em torno de 38 meses.

Inúmeros modelos de previsão de desempenho da sinalização horizontal já foram desenvolvidos, ponderandose, entre outros aspectos, o tempo necessário e/ou o volume de tráfego para alcançar os valores mínimos de retrorrefletividade. Ozelim e Turochy (2014) mostraram, em uma compilação de modelos de diversos trabalhos, o quão árdua é a tarefa de desenvolver um modelo fidedigno de previsão da perda de retrorrefletividade. O modelo dos autores resultou em um índice de correlação de 0,50, ainda baixo, mas superior à média dos modelos revisados.

Outros trabalhos focam a influência de fatores externos na retrorrefletividade. Lundkvist e Isacsson (2007) criaram um modelo que permite estimar a retrorrefletividade de demarcações com lâmina d'água com base na retrorrefletividade delas secas. Mull e Stizabee (2012), por sua vez, verificaram que a cada remoção de neve da superfície do pavimento, reduzia-se em um mês (redução de 3,22mcd $/ \mathrm{m}^{2} / \mathrm{lux}$ ), o tempo de vida útil da pintura de sinalização horizontal. Todos os estudos supracitados foram realizados com retrorrefletômetros de geometria de $30 \mathrm{~m}$.

\section{MÉTODO DE AVALIAÇÃO DE RETRORREFLETIVIDADE}

\subsection{Os Segmentos Experimentais}

O trecho rodoviário $(R O D)$ encontra-se na BR-158, próximo ao município de Júlio de Castilhos no interior do estado do Rio Grande do Sul. A rodovia é de pista simples com velocidade máxima permitida de $80 \mathrm{~km} / \mathrm{h}$; estima-se um volume diário médio (VDM unidirecional) de 3.000 veículos.

A pintura de demarcação foi realizada em outubro de 2010 com tinta acrílica (branca e amarela) à base de solvente, microesferas do Tipo I-B, misturadas à tinta antes da aplicação (premix) e microesferas do tipo II-A aspergidas sobre a tinta no momento da aplicação (drop-on). A composição da tinta, segundo dados de dosagem empregada, foi dotada de resina acrílica, cargas minerais, solventes aromáticos e alifáticos, dióxido de titânio e cromato de chumbo. Em relação às microesferas, a taxa de aplicação foi de $200 \mathrm{~g} / \mathrm{l}$ para o premix e $300 \mathrm{~g} / \mathrm{m}^{2}$ para o drop-on. Após a aplicação e secagem da tinta, foram instalados os dispositivos auxiliares (tachas) em todas as faixas. A Figura 1 demonstra o segmento rodoviário avaliado. 


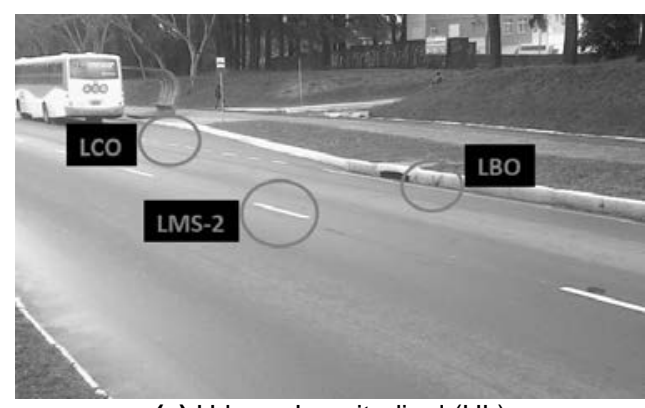

(a) Urbano Longitudinal (UL)



(b) Urbano Transversal (UT) Fonte: Google Earth

Figura 2. Demarcações dos trechos TU1 e TU2

Os dois trechos urbanos encontram-se na Av. Roraima (pista dupla com canteiro central e duas faixas por sentido) que liga a Universidade Federal de Santa Maria (UFSM) a BR-287, em que trafegam, diariamente, em média, 10.000 veículos (unidericionais), com velocidade máxima permitida de $50 \mathrm{~km} / \mathrm{h}$. Estes segmentos foram abertos ao tráfego em abril de 2012 (data da aplicação das demarcações) e seu monitoramento ocorreu de maneira sistemática até maio de 2014, completando os mesmos dois anos de avaliações, conforme ocorrera para o caso rodoviário.

O trecho urbano longitudinal (UL) é composto de dois segmentos exatamente iguais distanciados em 200m, com demarcações de coloração branca de eixo (linha simples seccionada - LMS2) e de bordo, sendo contínua (linha de bordo comum - LBO) e seccionada (linhas de continuidade - LCO), onde assume a função de demarcar a entrada de ônibus na parada conforme é mostrado na Figura 2a.

Nas LMS-2 foram realizadas três leituras em cada traço da sinalização; no LBO, o retrorrefletômetro foi posicionado sempre no mesmo ponto, totalizando 48 leituras por levantamento; já no LCO, cada traço recebeu uma leitura, somando 40 leituras por levantamento.

O material de demarcação termoplástico foi empregado nos segmentos do trecho UL. Nestes, ocorreu a aspersão do termoplástico com microesferas tipo Tipo I-A, incorporadas previamente ao material (innermix ou intermix), e microesferas de vidro Tipo II-A, incorporadas ao material durante a aplicação no trecho (drop-on). De acordo com os ensaios de caracterização, a constituição do material termoplástico possuia $22 \%$ de ligante, $22 \%$ de microesferas de vidro (innermix ou intermix - Tipo I-A), massa específica de $2,09 \mathrm{~kg} / \mathrm{L}$ e têm como pigmento o dióxido de titânio (TiO2) na proporção de 9,4\%. No momento de aplicação da sinalização, a temperatura do material termoplástico no tanque de armazenagem era de $190^{\circ} \mathrm{C}$ e o consumo de material na ordem de $3,5 \mathrm{~kg} / \mathrm{m}^{2}$. A microesfera Tipo II-A foi empregada a uma taxa de $400 \mathrm{~g} / \mathrm{m}^{2}$. A espessura final da massa termoplástica variou entre 3 e 3,5mm.

O segmento experimental urbano transversal (UT) é dotado de onze marcas transversais de coloração branca, conhecidas como linhas de estímulo à redução de velocidade (Figura 2b). Neste segmento, oito das marcas transversais foram pintadas com mesmo material descrito acima, porém, em caráter comparativo, outras três linhas transversais foram pintadas com tinta acrílica com premix seguidas de drop-on, com demarcações realizadas com tinta acrílica semelhante àquela implementada no trecho rodoviário.

\subsection{Equipamentos Empregados e Procedimento de Avaliação da Retrorrefletividade}

Os levantamentos no segmento rodoviário foram realizados com o equipamento A de geometria de 30m (afora a geometria do equipamento, todo o procedimento seguiu a norma ABNT (2005): no bordo esquerdo (linha contínua $\operatorname{Rod}_{\text {bordo }}$ ) e no eixo (intermitente e/ou contínua - $\operatorname{Rod}_{\text {eixo }}$ ), em estações entre os $\mathrm{km} 280$ e 290, durante os primeiros dois anos das demarcações (2010 a 2012).

Os levantamentos em ambiente urbano foram conduzidos com equipamento B que permite a medida em dupla geometria, simulando distâncias de visibilidade de 15 e $30 \mathrm{~m}$, o que possibilitou a realização de uma medição dupla em cada levantamento além de levar em conta os procedimentos e normas brasileiros. Cabe ressaltar que o retrorrefletômetro de geometria de $15 \mathrm{~m}$ (norma nacional) aferiu a retrorrefletividade com o ângulo de observação de $1,5^{\circ}$ e ângulo de incidência de $86,5^{\circ}$; já na geometria de $30 \mathrm{~m}$ (normas internacionais), os ângulos são de $1,05^{\circ}$ e $88,76^{\circ}$, respectivamente.

Os levantamentos obedeceram à metodologia da norma ABNT (2005), vigente à época. Primeiramente, procedia-se a limpeza da demarcação com emprego de vassoura. Após a limpeza, posicionava-se o equipamento realizando dez leituras, deslocando o retrorrefletômetro em torno de $30 \mathrm{~cm}$ a cada medida de $\mathrm{R}_{\mathrm{L}}$. Estes dez valores não poderiam variar mais do que $15 \%$ (no caso de valores altos de retrorrefletividade: $R_{L}>250$ mcd. ${ }^{-2} \cdot l_{u x}{ }^{-1}$ ), e mais do que $30 \%$ (em caso de valores baixos de retrorrefletividade: $\mathrm{R}_{\mathrm{L}}<250$ mcd. $\left.\mathrm{m}^{-2} \cdot \mathrm{lux}^{-1}\right)$.

Após este procedimento, o maior e o menor valor eram descartados e com os oito valores restantes calculavase a média aritmética que seria alusiva ao valor de retrorrefletividade representativa do elemento analisado. Todas as análises propostas neste trabalho seguiram a mesma sistemática, compatível com o tratamento estatístico indicado pela norma brasileira; diga-se em tempo, extremamente elementar. Nenhuma medida de retrorrefletividade fora conduzida com a umidade relativa do ar superior a $90 \%$, seguindo ABNT (2005).

De maneira geral, realizaram-se as primeiras medidas de retrorrefletividade dos segmentos logo após a pintura, imediatamente após a secagem da tinta ou resfriamento do material termoplástico (antes da liberação do tráfego), denominando-as de $\mathrm{R}_{\mathrm{L}}$ imediata. Transcorridas 24 horas da abertura ao tráfego, foram realizados os levantamentos da 
Tabela 1. Retrorrefletividade no trecho urbano longitudinal (UL)

\begin{tabular}{lccccccc}
\hline \multicolumn{7}{c}{ Urbano Longitudinal } \\
\hline \multirow{2}{*}{ Dias } & \multirow{2}{*}{ VDM (unidirecional) } & $\begin{array}{c}\text { UL-LMS2 } \\
(15)\end{array}$ & $\begin{array}{c}\text { UL-LCO } \\
(15)\end{array}$ & $\begin{array}{c}\text { UL-LBO } \\
(15)\end{array}$ & $\begin{array}{c}\text { UL-LMS2 } \\
(30)\end{array}$ & $\begin{array}{c}\text { UL-LCO } \\
(30)\end{array}$ & $\begin{array}{c}U L-L B O \\
(30)\end{array}$ \\
\hline $0\left(\mathrm{Rl}_{\text {imediata }}\right)$ & $0,00 \mathrm{E}+00$ & 605,5 & 459,8 & 534,4 & 198,8 & 143,6 & 172 \\
$1(\mathrm{Rl}$ inicial) & $1,00 \mathrm{E}+04$ & 737,0 & 602,2 & 542,0 & 339,8 & 291,5 & 183,8 \\
15 & $1,60 \mathrm{E}+05$ & 565,6 & 388,5 & 429,5 & 286,7 & 214,3 & 156,6 \\
35 & $5,10 \mathrm{E}+05$ & 594,8 & 438,2 & 498,6 & 315,9 & 279,9 & 217,9 \\
62 & $1,13 \mathrm{E}+06$ & 296,0 & 254,7 & 271,5 & 169,1 & 145,1 & 104,5 \\
94 & $2,07 \mathrm{E}+06$ & 374,4 & 240,1 & 206,8 & 194,6 & 135,6 & 89,8 \\
197 & $4,04 \mathrm{E}+06$ & 410,2 & 241,4 & 210,8 & 197,5 & 127,7 & 95,2 \\
231 & $6,35 \mathrm{E}+06$ & 317,8 & 170,7 & 173,8 & 155,3 & 86,6 & 69,0 \\
267 & $9,02 \mathrm{E}+06$ & 375,0 & 216,8 & 219,6 & 177,2 & 107,9 & 85,4 \\
322 & $1,22 \mathrm{E}+07$ & 272,2 & 160,3 & 190,6 & 147,2 & 86,1 & 84,7 \\
359 & $1,58 \mathrm{E}+07$ & 348,1 & 197,1 & 224,4 & 187,6 & 105,4 & 104,5 \\
419 & $2,00 \mathrm{E}+07$ & 231,2 & 126,2 & 128,1 & 150,4 & 80,8 & 66,0 \\
491 & $2,49 \mathrm{E}+07$ & 186,8 & 111,9 & 105,2 & 112,9 & 79,7 & 50,0 \\
568 & $3,06 \mathrm{E}+07$ & 179,7 & 129,3 & 117,1 & 111,2 & 70,1 & 60,8 \\
650 & $3,71 \mathrm{E}+07$ & 180,5 & 132,4 & 116,1 & 99,7 & 64,8 & 54,1 \\
708 & $4,42 \mathrm{E}+07$ & 167,8 & 122,8 & 101,4 & 101,2 & 72,2 & 51,5 \\
771 & $5,19 \mathrm{E}+07$ & 131,8 & 98,9 & 103,5 & 78,0 & 51,7 & 50,9 \\
\hline
\end{tabular}

retrorrefletividade inicial $\left(\mathrm{R}_{\mathrm{L}}\right.$ inicial). Afora estas primeiras medidas, qualquer outra obtida posteriormente foi chamada de retrorrefletividade residual $\left(\mathrm{R}_{\mathrm{L}}\right.$ residual) na idade "i"dias.

\section{DESEMPENHO DE RETRORREFLETIVIDADE NOS TRECHOS EXPERIMENTAIS E ANÁLISES}

Os resultados de evolução da retrorrefletividade média dos distintos dispositivos de demarcação viária estão dispostos nas Tabelas 1, 2 e 3. Nas Figuras 3 e 4, tem-se a evolução do parâmetro com o tempo; já nas Figuras 5 e 6 com o tráfego acumulado. As Figuras 3 e 4 diferem-se pela geometria da avaliação (15m e $30 \mathrm{~m})$, o mesmo ocorrendo com as Figuras 5 e 6.

Primeiramente, como esperado, nota-se uma clara superioridade de valores de retrorrefletividade dos dispositivos aferidos em mesma idade com a geometria de $15 \mathrm{~m}$ em relação aos medidos pela geometria de $30 \mathrm{~m}$. Quanto mais distante do foco de luz for a simulação do aparelho, menores serão os valores mensurados; para todas as demarcações, os valores iniciais de retrorrefletividade foram maiores quando medidos com a geometria de $15 \mathrm{~m}$.

Com relação aos distintos materiais aplicados nas demarcações transversais urbanas, o desempenho da retrorrefletividade do termoplástico é visivelmente superior à da tinta acrílica (em qualquer geometria). Este desempenho foi tão superior que mesmo antes de 231 dias (7,7 meses), a demarcação transversal com tinta termoplástica e aferida com a geometria de $30 \mathrm{~m}$, já apresentava desempenho superior ao da acrílica medida com a geometria de 15m (menos rigorosa) - vide Tabela 2 e Figuras 3 e 4.

No trecho rodoviário, a retrorrefletividade da demarcação branca (bordo) é superior à amarela (eixo), como esperado. Na $\mathrm{R}_{\mathrm{L}}$ inicial, essa superioridade é de $28 \%$ decorrente da claridade natural da cor branca que retorna mais luz ao receptor. Entretanto, ao final dos dois anos, essa diferença foi de inversos 5\%, em função da maior perda de retrorrefletividade da demarcação de bordo (mesmo com a coloração branca favorecendo a pintura do bordo). Isso ocor- reu porque os bordos, ao serem menos solicitados pelos veículos, permitiram um maior acúmulo de sujeira sobre a demarcação, fato que também foi constatado nos segmentos urbanos, como será abordado ao longo do trabalho.

Nas Figuras 3 e 4, percebe-se que para os termoplásticos aplicados nas demarcações urbanas, há uma tendência de aumento de retrorrefletividade nos primeiros dias, seguido por uma brusca queda e uma pequena elevação nas semanas seguintes. O primeiro aumento dá-se em função do impacto inical do tráfego que retira o excesso de microesferas não ancoradas; uma elevada taxa de elementos retrorrefletivos pode ocasionar um efeito de ofuscamento e uma diminuição da retrorrefletividade real.

A queda conseguinte é decorrente do tráfego, agora, arrancando o drop-on ancorado na demarcação. O próximo aumento é também decorrente do tráfego que começa a desgastar o material termoplástico fazendo com que as primeiras microesferas do intermix fiquem expostas, em conformidade com Moreira e Menegon (2003).

Nas demarcações com tinta acrílica, tanto no segmento urbano quanto no rodoviário, essas oscilações não foram verificadas; a perda da propriedade retrorrefletiva foi contínua e, depois de 100 dias, tendeu a uma assíntota horizontal, mais suave para o caso rodoviário. Intui-se que a ancoragem de microesferas promovida pela tinta acrílica seja menor do que a do termoplástico. Ainda, o formato da curva de desgaste das tintas acrílicas (na rodovia ou via urbana) parece ser distinto daquela do termoplástico, não realçando a retrorrefletividade com o aparecimento do premix na superfície.

No trecho urbano, a retrorrefletividade avaliada no último levantamento das marcas transversais, implementadas com material termoplástico, foi mais que o dobro da média das demarcações longitudinais com o mesmo material. Aparentemente, este comportamento representaria uma histerese na degradação das pinturas transversais, uma vez que tais demarcações são sempre solicitadas pelos veículos, enquanto aquelas longitudinais não são submetidas à ação 
SALLES, L.S.; PEREIRA, D.S.; TEIXEIRA, D.L.K.; SPECHTL.P.

Tabela 2. Retrorrefletividade no trecho urbano transversal (UT)

\begin{tabular}{llll|llll}
\hline & \multicolumn{3}{c}{ Urbano Transversal Termoplástico } & \multicolumn{5}{c}{ Urbano Transversal Acrílica } \\
\hline Dias & VDM (unid.) & UT-TERM $(15)$ & UT-TERM (30) & Dias & VDM (unid.) & UT-ACRI (15) & UT-ACRI (30) \\
\hline $0\left(\mathrm{Rl}_{\text {imediata }}\right)$ & $0,00 \mathrm{E}+00$ & 377,2 & 101,6 & 0 & $0,00 \mathrm{E}+00$ & $\mathrm{NC}$ & $\mathrm{NC}$ \\
$1\left(\mathrm{Rl}_{\text {inicial }}\right)$ & $1,00 \mathrm{E}+04$ & 668,0 & 266,2 & 1 & $1,00 \mathrm{E}+04$ & $\mathrm{NC}$ & $\mathrm{NC}$ \\
15 & $1,50 \mathrm{E}+05$ & 543,3 & 246,6 & 15 & $1,50 \mathrm{E}+05$ & 508,2 & 191,9 \\
35 & $3,50 \mathrm{E}+05$ & 612,2 & 310,0 & 35 & $3,50 \mathrm{E}+05$ & 414,5 & 180,5 \\
62 & $6,20 \mathrm{E}+05$ & 368,0 & 193,4 & 62 & $6,20 \mathrm{E}+05$ & 221,4 & 103,9 \\
94 & $9,40 \mathrm{E}+05$ & 414,9 & 202,7 & 94 & $9,40 \mathrm{E}+05$ & 230,2 & 104,4 \\
197 & $1,97 \mathrm{E}+06$ & 402,2 & 199,4 & 197 & $1,97 \mathrm{E}+06$ & NC & NC \\
231 & $2,31 \mathrm{E}+06$ & 376,0 & 205,0 & 231 & $2,31 \mathrm{E}+06$ & 178,1 & 82,6 \\
267 & $2,67 \mathrm{E}+06$ & 439,0 & 235,0 & 267 & $2,67 \mathrm{E}+06$ & 204,2 & 87,2 \\
322 & $3,22 \mathrm{E}+06$ & 389,2 & 230,0 & 322 & $3,22 \mathrm{E}+06$ & 155,3 & 71,4 \\
359 & $3,59 \mathrm{E}+06$ & 420,4 & 250,1 & 359 & $3,59 \mathrm{E}+06$ & 191,4 & 91,0 \\
419 & $4,19 \mathrm{E}+06$ & 304,7 & 194,1 & 419 & $4,19 \mathrm{E}+06$ & 127,3 & 72,4 \\
491 & $4,91 \mathrm{E}+06$ & 305,4 & 162,7 & 491 & $4,91 \mathrm{E}+06$ & 119,4 & 58,6 \\
568 & $5,68 \mathrm{E}+06$ & 274,1 & 164,6 & 568 & $5,68 \mathrm{E}+06$ & 126,4 & 64,8 \\
650 & $6,50 \mathrm{E}+06$ & 285,9 & 168,8 & 650 & $6,50 \mathrm{E}+06$ & 97,1 & 49,4 \\
708 & $7,08 \mathrm{E}+06$ & 250,1 & 161,0 & 708 & $7,08 \mathrm{E}+06$ & 98,4 & 49,4 \\
771 & $7,71 \mathrm{E}+06$ & 228,3 & 133,3 & 771 & $7,71 \mathrm{E}+06$ & 85,9 & 42,7 \\
\hline
\end{tabular}

NC = Não Consta (não foi medido)

abrasiva dos pneus em todas as operações veiculares, promovendo, assim, um menor desgaste (nas longitudinais).

Pode-se explicar este comportamento atípico pelo fato de os levantamentos das marcas transversais terem sido divididos em cinco pontos para cada faixa de rolagem (vide Figura 7), sendo, sobretudo, os pontos 2 e 4 coincidentes com as trilhas de roda (acarretando em um maior desgaste).

Na Figura 7 (dados do último levantamento), os pon-

tos 2 e 4 na trilha de roda apresentam um valor de retrorrefletividade bastante parecido com aquele das marcas longitudinais; entretanto, a média das demarcações transversais é ampliada pela retrorrefletividade dos pontos 1 e 5, onde houve desgaste consideravelmente inferior.

Depreende-se, ainda, da Figura 7, que a faixa de rolagem interna (lado esquerdo - LE), principalmente nas porções coincidentes com as trilhas de roda, apresentou re trorrefletividade superior àquela do lado direito (faixa externa). A despeito do tráfego aferido na faixa interna ser 15\% superior ao da faixa da direita (volume diário médio

\begin{tabular}{llll} 
Tabela 3. Retrorrefletividade no trecho rodoviário (ROD) \\
\hline \multicolumn{4}{c}{ Rodoviário } \\
\hline \multirow{2}{*}{ Dias } & VDM & $\begin{array}{l}\text { ROD } \\
\text { Bordo }\end{array}$ & $\begin{array}{l}\text { ROD Eixo } \\
(30)\end{array}$ \\
\hline $0\left(\mathrm{Rl}_{\text {imediata }}\right)$ & $0,00 \mathrm{E}+00$ & 291,1 & 195,4 \\
$1\left(\mathrm{Rl}_{\text {inicial}}\right)$ & $3,00 \mathrm{E}+03$ & 215,7 & 154,5 \\
7 & $2,10 \mathrm{E}+04$ & 191,5 & 117,0 \\
30 & $9,00 \mathrm{E}+04$ & 134,3 & 100,0 \\
60 & $1,80 \mathrm{E}+05$ & 113,9 & 89,3 \\
90 & $2,70 \mathrm{E}+05$ & 105,4 & 84,9 \\
150 & $4,50 \mathrm{E}+05$ & 71,0 & 48,1 \\
400 & $1,20 \mathrm{E}+06$ & 62,7 & 52,8 \\
800 & $2,40 \mathrm{E}+06$ & 42,8 & 45,1 \\
\hline
\end{tabular}

unidirecional de 10.000 veículos totais), justifica-se este comportamento pela tendência natural dos veículos pesados, que geram maior abrasão sobre a pintura de demarcação, trafegarem, preferencialmente, sobre a pista da direita (85\% dos 635 veículos comerciais que trafegam, diariamente, sobre a pista urbana em estudo).

\subsection{Influência da precipitação pluviométrica}

Ao serem analisados os dados de retrorrefletividade, percebeu-se após 200 dias de liberação do tráfego, oscilações importantes na retrorrefletividade dos segmentos urbanos (Figuras 3 e 4). Na Figura 8 é apresentada a evolução da retrorrefletividade (geometria de $15 \mathrm{~m}$ ) no trecho urbano das pinturas termoplásticas e acrílicas, conjuntamente com os dados da precipitação pluviométrica acumulada nos três dias anteriores ao levantamento.

Nota-se que sempre antes dos levantamentos em que incorreram as maiores elevações de retrorrefletividade (dias 267 e 359), os índices acumulados (três dias) ficaram próximos de $50 \mathrm{~mm}$. Igual tendência foi verificada para as avaliações com geometria de $30 \mathrm{~m}$.

É natural que após os primeiros meses, o drop-on tenha sido removido parcial ou totalmente da superfície da demarcação pela ação abrasiva do tráfego. Portanto, as oscilações evidenciadas na Figura 8, provavelmente advenham da interação dos pneus com a água da chuva que removem a sujeira depositada sobre a pintura e as microesferas (premix ou innermix/intermix expostas pelo desgaste das pinturas), potencializando a retrorrefletividade e a coloração alva da demarcação viária urbana.

Obviamente que durante a chuva, há significativa redução da retrorrefletividade pela formação de uma película 


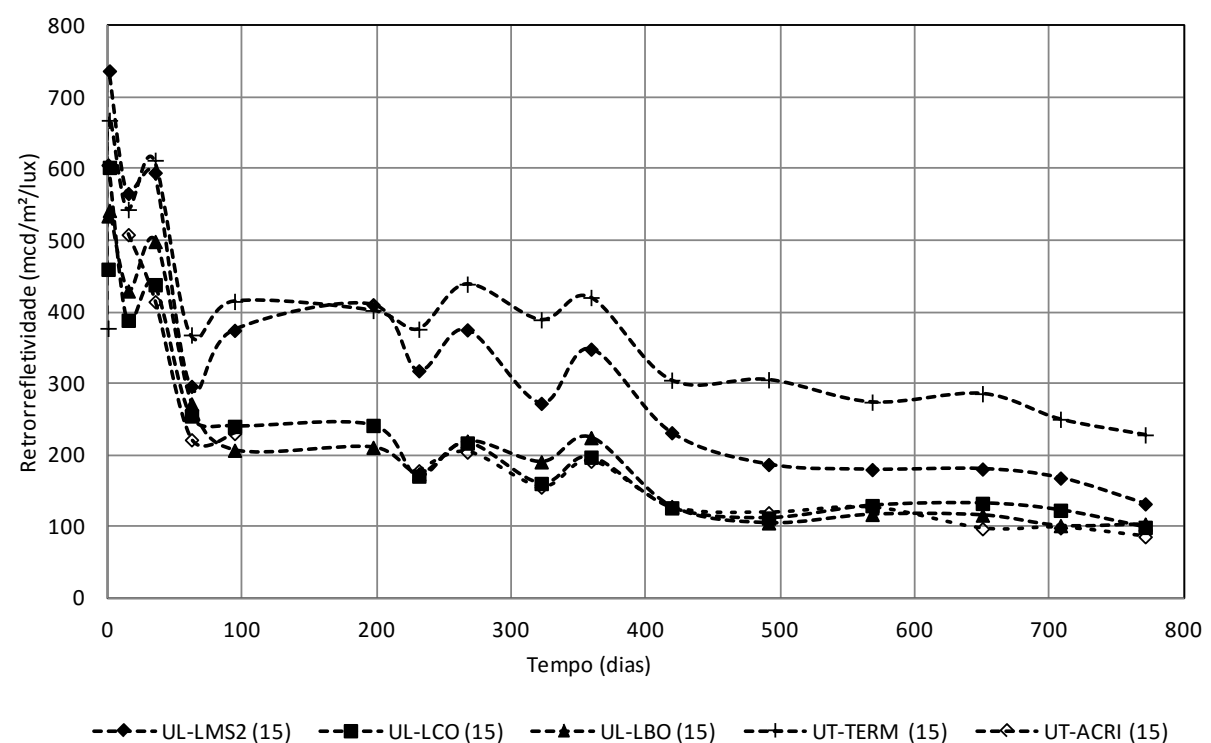

Figura 3. Evolução da retrorrefletividade (geom. 15m) com o tempo (dias)

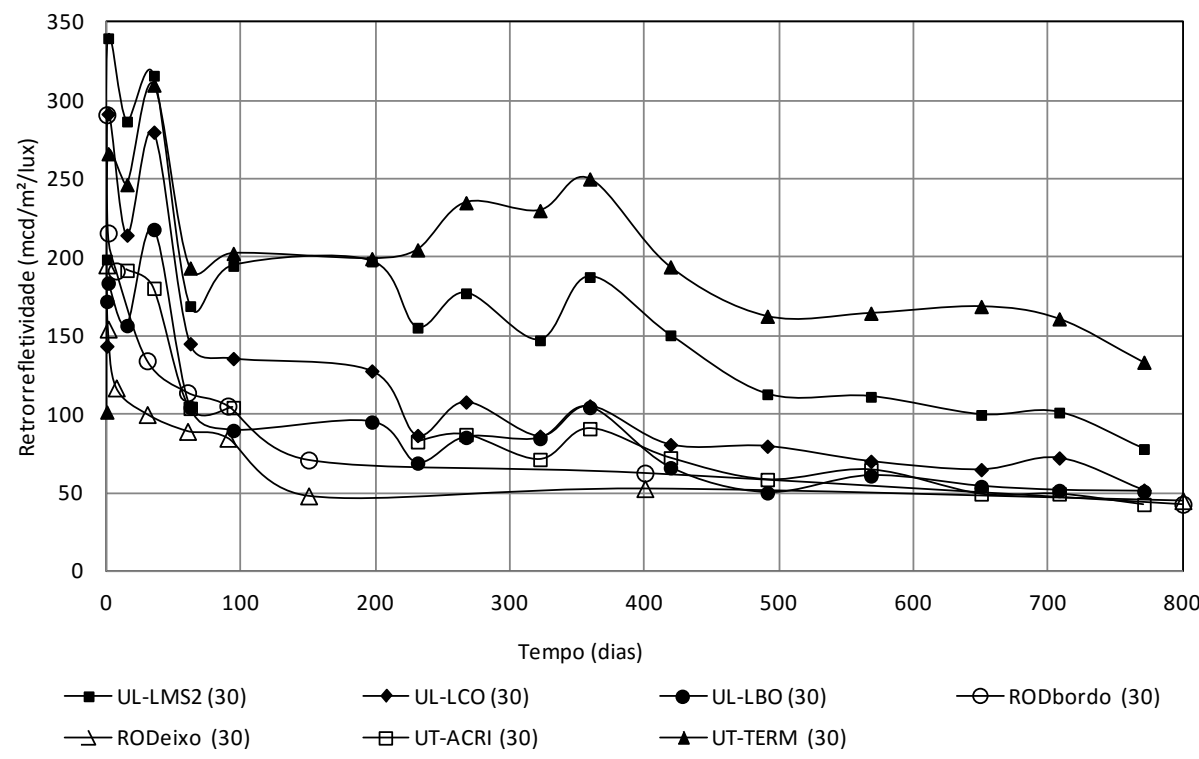

Figura 4. Evolução da retrorrefletividade (geom. 30m) com o tempo (dias)

de água que diminui a capacidade retrorrefletiva da sinalização horizontal; porém, no período pós-precipitação, com o auxílio da abrasão do tráfego, a chuva potencializa a limpeza das demarcações. Nas demarcações transversais, esta melhoria foi mais pronunciada naquelas pintadas com tinta acrílica.

No tocante às longitudinais termoplásticas, houve leve predomínio de melhoria nas demarcações UL-LCO (vide Figura 2a), onde a entrada e saída de ônibus produziu maior ação abrasiva e, consequentemente, de limpeza da superfície. Nos dois picos verificados na Figura 8, houve um acréscimo médio da retrorrefletividade (geom. 15m) de 25\% para a UL-LCO (15), 23\% para a UL-LMS2 (15), 22\% para a UL-LBO (15), 19\% para a UT-ACRI (15) e 12,5\% para a UT-TERM (15).

Todavia, essa melhoria parece ser função do intervalo de tempo entre a precipitação pluviométrica e o levantamento; chuvas que ocorreram uma semana antes dos levantamentos não apresentaram qualquer impacto sobre a melhoria da retrorrefletividade. Precipitações acumuladas (três dias) abaixo de $30 \mathrm{~mm}$, não melhoraram a retrorrefletividade de um levantamento para o outro, mas mascaram positivamente o declínio do parâmetro.

Devido à inexistência de estação meteorológica próxima ao segmento rodoviário avaliado, não foi possível registrar dados de chuva que permitissem, com adequada confiança, intuir sobre esta influência a respeito da limpeza e/ou melhoria da retrorrefletividade, todavia há indícios do mesmo comportamento.

Não é desejo, contudo, concluir cabalmente que a chuva ou a umidade, seja um efeito climático de todo benéfico para o desempenho da pavimentação. Pontualmente, conforme verificado neste estudo, a precipitação pode ser considerada salutar para a retrorrefletividade. Para os autores, é intuitivo pensar que a umidade e/ou filme de água presente na superfície da demarcação viária, quando avaliados isoladamente, contribuam para o aumento da velocidade de degradação da retrorrefletividade. Infelizmente, em função da relativa escassez de bibliografia, não foram encontrados trabalhos científicos que particularizaram este fenômeno, correlacionando-o com o desempenho das demarcações. 


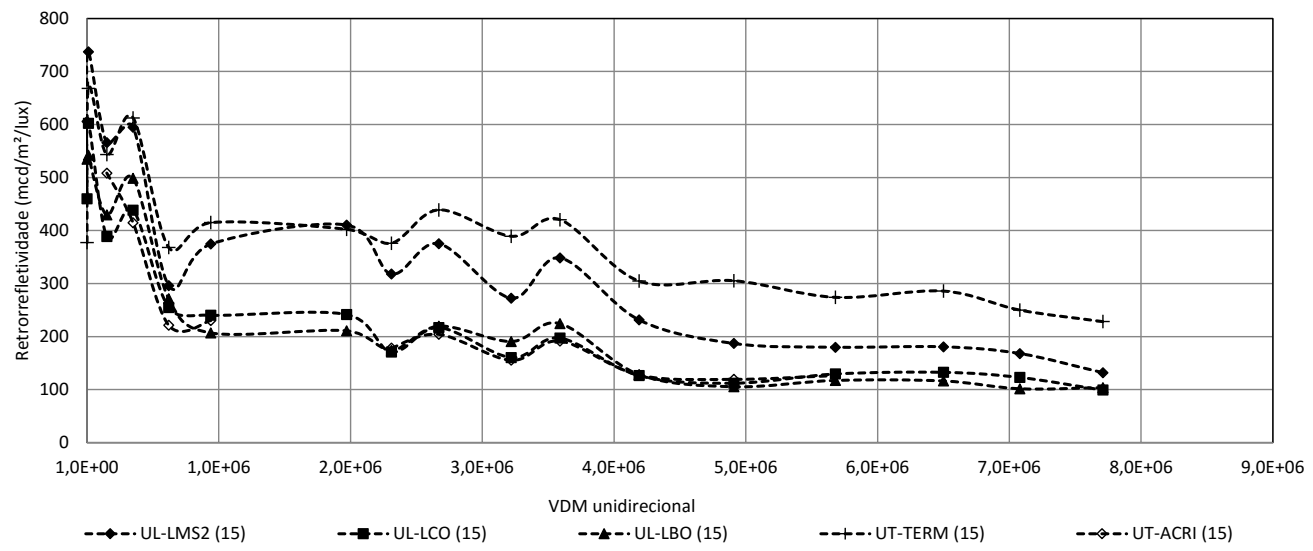

Figura 5. Evolução da retrorrefletividade (geom. 15m) com o VDM

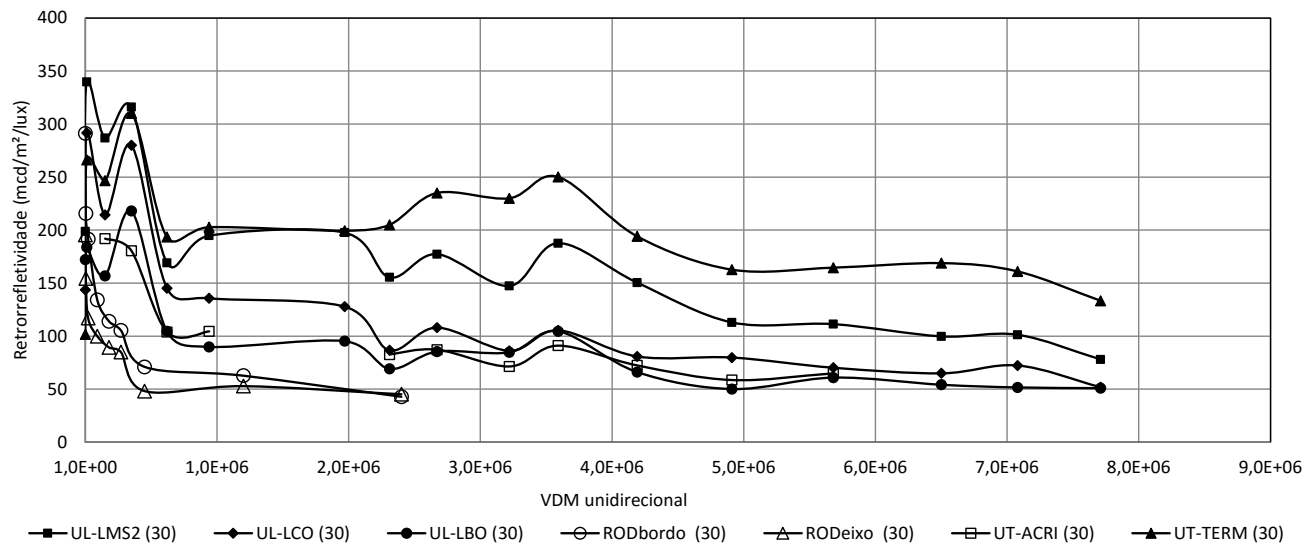

Figura 6. Evolução da retrorrefletividade (geom. 30m) com o VDM

\subsection{Impacto da ação de limpeza sobre a retrorrefletividade}

Para verificar ativamente o efeito de limpeza da chuva, realizou-se em um dia seco do mês de setembro de 2014, a limpeza com água (simulando a chuva) e escovação leve (comparável ao efeito abrasivo do tráfego) de alguns pontos do eixo (UL-LMS-2) e bordo (UL-LBO) da demarcação longitudinal no trecho urbano. Os resultados estão apresentados na Figura 9, onde percebe-se que sempre ocorreu aumento da retrorrefletividade com a ação de limpeza (apresentou-se os resultados com geometria de $15 \mathrm{~m}$ mas o comportamento foi análogo para a geometria de $30 \mathrm{~m}$ ).

Apesar de o acréscimo ter ocorrido para ambas as posições, houve maior efetividade da limpeza exercida no bordo (75\%) em relação ao eixo (19\%). Pode-se atribuir dois fatores para esta diferença. Primeiramente, por tratarse de segmento urbano com a presença de meio-fio e inexistência de acostamento, o pavimento fica confinado, permitindo maior acúmulo de sujeira junto ao bordo. Soma-se o fato de no bordo, com as condições do experimento urbano, a demarcação ter sido raramente solicitada pelos veículos, preservando melhor suas propriedades retrorrefletiva que, durante o tempo de avaliação, teve seu decréscimo bastante influenciado pela sujeira depositada sobre a mesma. No eixo, com maior ação do tráfego, o desgaste da pintura é maior, reduzindo sua potencial melhoria por efeito da limpeza.
No trecho rodoviário o acúmulo de sujeira na sinalização é menor, sobretudo no bordo, e os efeitos da limpeza não foram tão sensíveis devido à ausência da contenção lateral (meio-fio), à presença do acostamento e à maior declividade lateral.

Em relação ao tipo de demarcação do trecho urbano longitudinal, a combinação chuva mais abrasão do tráfego apresentou resultados interessantes conforme anteriormente explorado. Justamente por sofrer a ação da chuva e do tráfego mais intensamente, a linha de eixo (LMS-2) apresentou os maiores valores de retrorrefletividade; entretanto, deve-se ressaltar que o tráfego que passa pelo eixo é, em sua maioria, constituído de veículos leves em mudança de faixa. $\mathrm{Na}$ linha de bordo de entrada para os pontos de ônibus (LCO) também ocorre a interação água da chuva e tráfego, porém agora, com veículos muito mais pesados e potencialmente mais danosos à demarcação.

Na linha de bordo contínuo (LBO) não existe a passagem direta do tráfego, isso eleva o acúmulo de sujeira na demarcação (Figura 10) mesmo após períodos chuvosos, pois não há a ação de “escovação” do tráfego. Como as duas linhas de bordo, LCO e LBO, apresentaram valores semelhantes de retrorrefletividade ao longo dos dois anos de experimento, pressupõe-se que o efeito abrasivo de veículos 
Avaliação retrorrefletiva de pintura de demarcação horizontal: peculiaridades ...

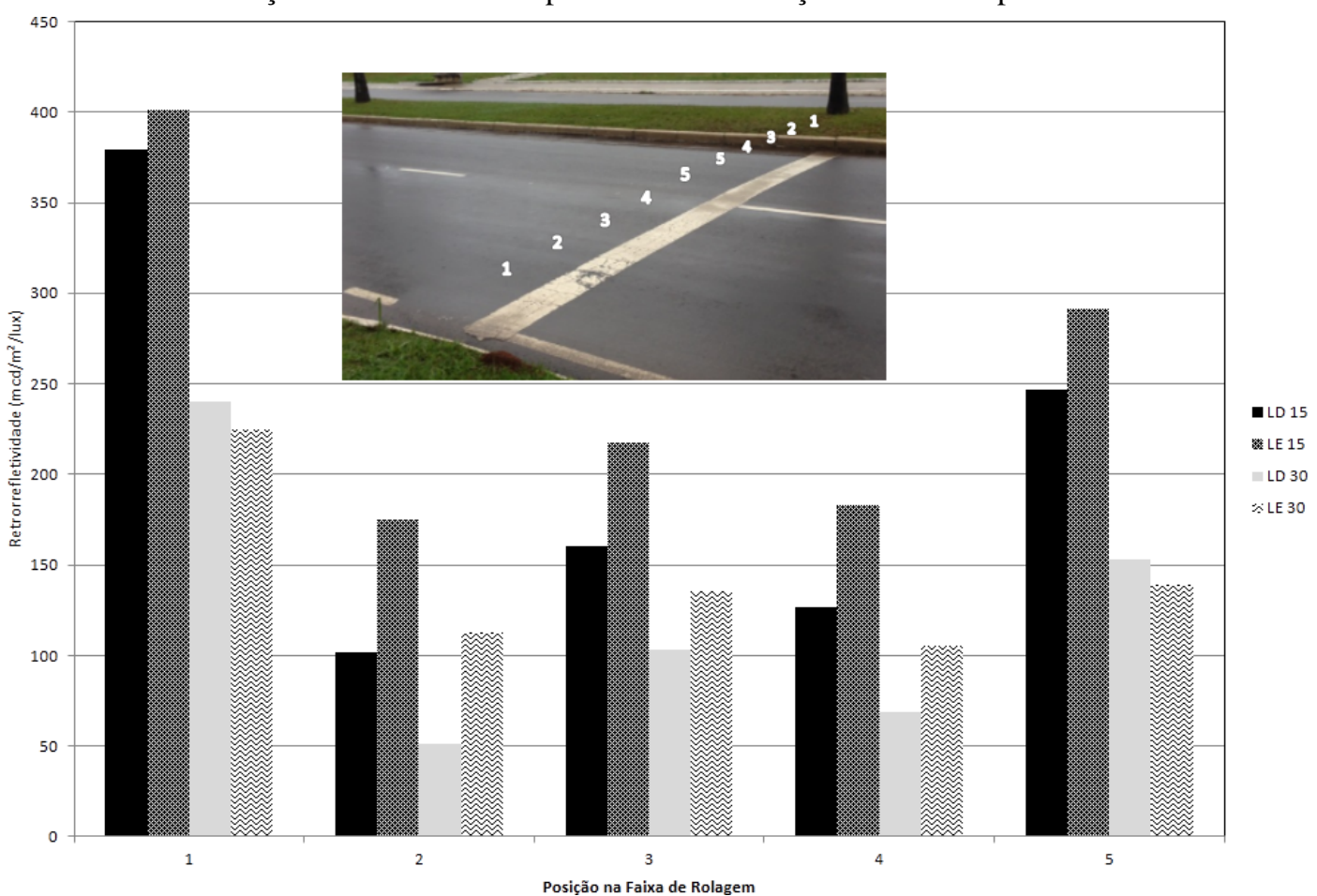

Figura 7. Retrorrefletividade por ponto nas demarcações transversais (termoplástico)

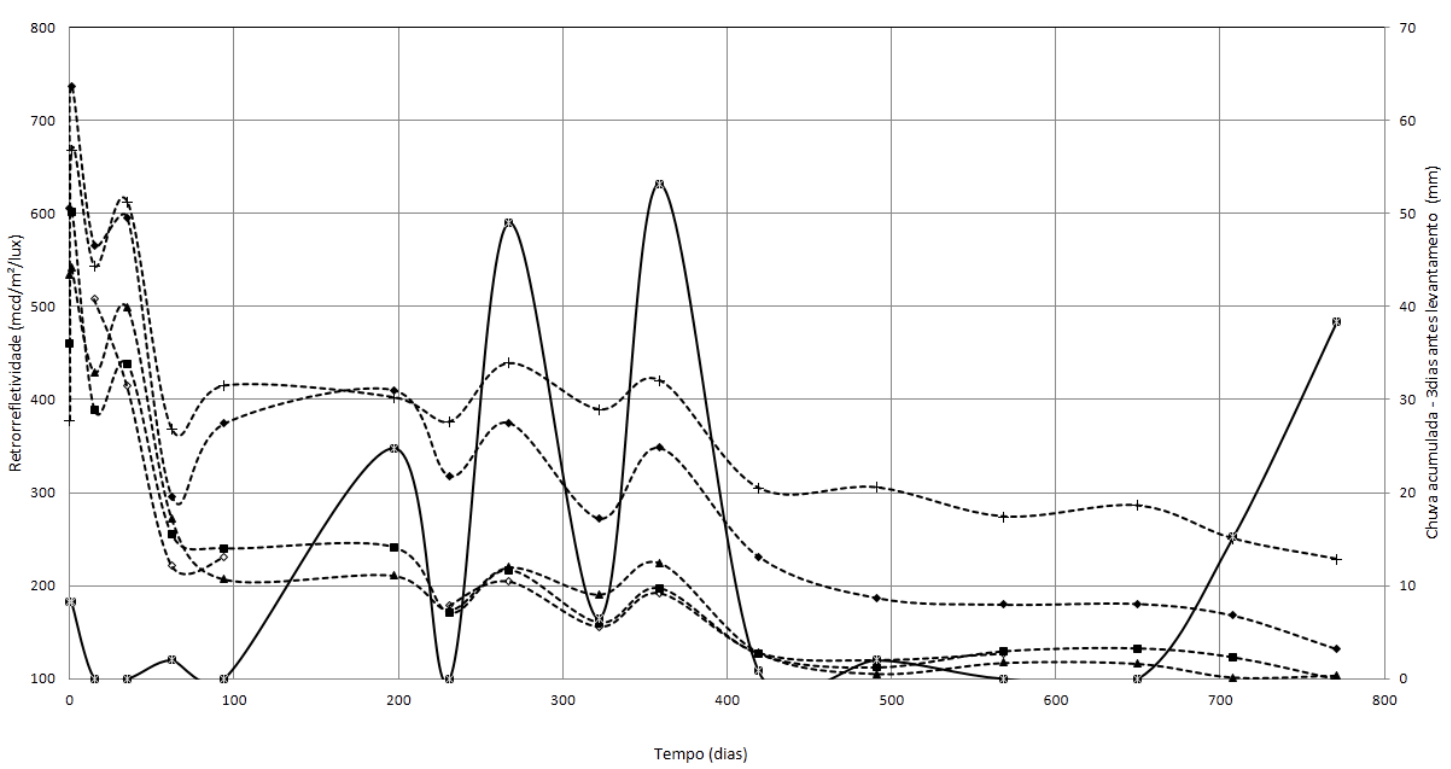

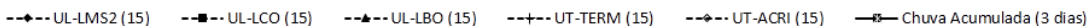

Figura 8. Retrorrefletividade (15m) vs. Precipitação Acumulada (3 dias antes do levantamento)

pesados e lentos (ônibus) seja equivalente em potencial danoso à retrorrefletividade ao acúmulo de sujeira nas demarcações. Contudo, o segundo é reversível.

\section{FATOR DE CORRELAÇÃO ENTRE GEOMETRIAS (FCG) E RETRORREFLETÔMETROS (FCR)}

Para que seja possível avaliar comparativamente o desempenho da sinalização horizontal aferido segundo a ABNT (2005) com os parâmetros mínimos internacionais de retrorrefletividade, fez-se necessária a determinação de um Fator de Correlação entre Geometrias (FCG). Isto foi possível através do emprego do retrorrefletômetro $B$, capaz de inferir a qualidade da demarcação viária em ambas as geometrias (15m e 30m). Todas as avaliaçõs dos trechos urbanos foram conduzidas com este equipamento.

Através da relação direta entre as médias de retrorrefletividade das Tabelas 1 e 2 chega-se a um fator de correlação (FCG) médio entre as geometrias de 15 e 30m de 2,05 (desvio-padrão de 0,40 e CV de 19,8\%). Isso significa que as avaliações realizadas com a geometria de $30 \mathrm{~m}$ são cerca de duas vezes mais rigorosas do que aquelas realizadas com a geometria de $15 \mathrm{~m}$ o que é bastante intuitivo, visto a diferença métrica das geometrias.

O trecho rodoviário foi avaliado com o equipamento A (geometria única de $30 \mathrm{~m}$ ); porém o equipamento B já estava disponível no último levantamento, permitindo a comparação entre os dois retrorrefletômetros. Para tanto, os equipamentos A e B foram posicionados sempre no mesmo 


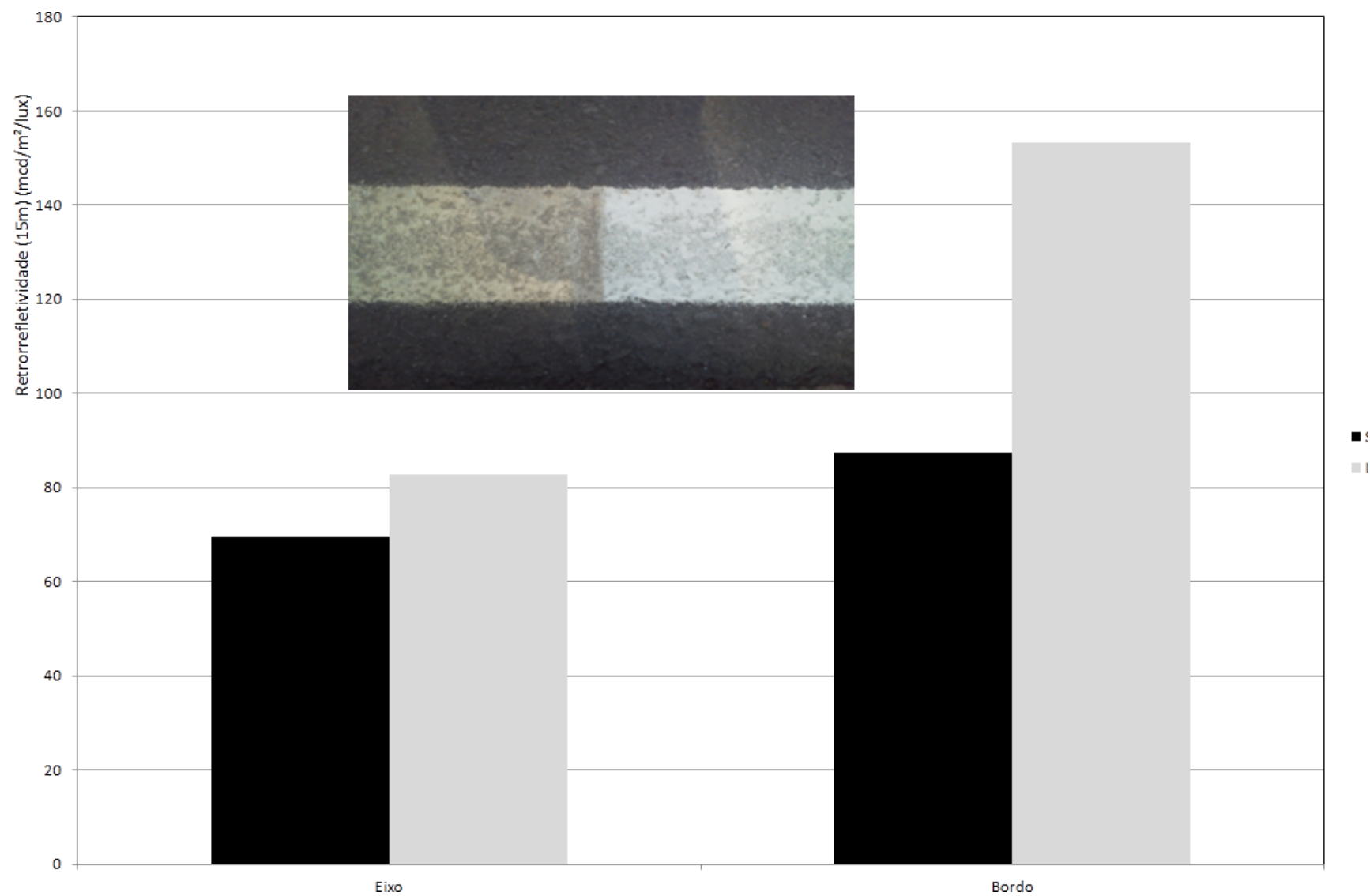

Figura 9. Efeito da limpeza na retrorrefletividade do trecho urbano

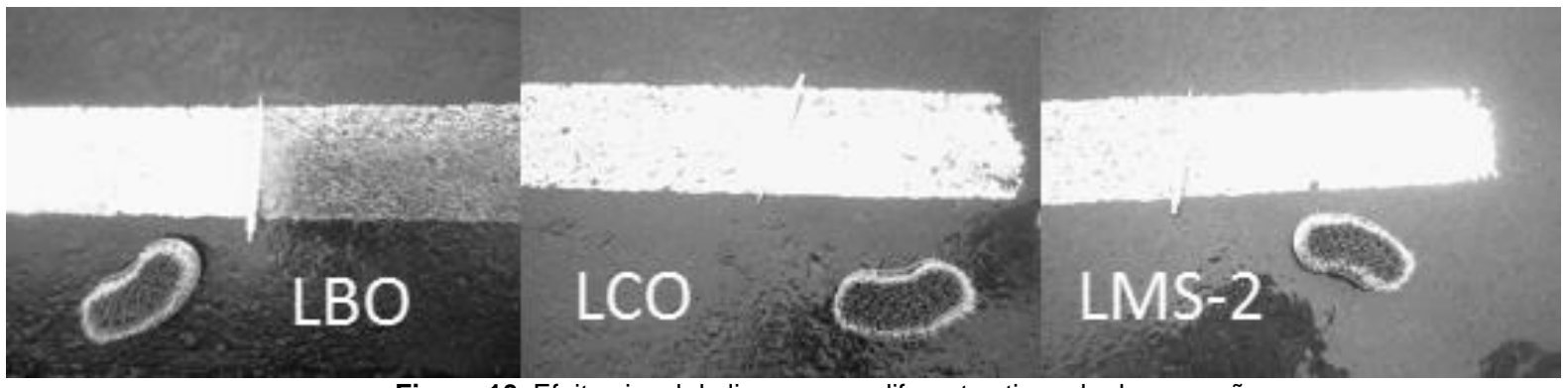

Figura 10. Efeito visual da limpeza em diferentes tipos de demarcação

ponto. A Tabela 4 demonstra os resultados. O fator de conversão entre retrorrefletômetros, equipamento B em relação ao $\mathrm{A}\left(\mathrm{FCR}_{\mathrm{B} / \mathrm{A}}\right)$ resultou em valor médio de 0,79 (desvio-padrão de 0,14 e CV de $17,7 \%$ ); ou seja, o equipamento B mede valores menores de retrorrefletividade na geometria de 30m. Supõe-se que esse fato decorre de fatores referentes à calibração do equipamento, pois ambos possuem a mesma geometria angular.

\section{DESEMPENHO DA RETRORREFLETIVIDADE FRENTE A PARÂMETROS NORMATIVOS OU RECOMENDAÇÕES}

Na Tabela 5 é apresentada a avaliação final da retrorrefletividade frente a normas, agências reguladoras e recomendações nacionais e internacionais. Os valores do trecho rodoviário medidos com o retrorrefletômetro A foram corrigidos para representarem a geometria de 15 m (parâmetros nacionais) com o FCG. Para padronizar os valores de mesma geometria (30m) obtidos com equipamentos diferentes, empregou-se o FCR $_{\mathrm{B} / \mathrm{A}}$ para uniformização das leituras realizadas com o retrorrefletômetro A. Os valores que não atendem aos requisitos mínimos de cada referência estão destacados na Tabela 5.

Nota-se que o trecho rodoviário somente estaria adequado perante às recomendações europeias em período chuvoso, mas que deveria ser avaliado de maneira distinta e ainda mais severa (Gibbons et al., 2013); com tempo seco, as demarcações não atenderiam aos requisitos de segurança.

Novamente, é visível a superioridade do material termoplástico em relação às tintas acrílicas; em função do menor desgaste da demarcação e do melhor suporte às microesferas; os valores de retrorrefletividade são sempre maiores para os termoplásticos fazendo com que o trecho urbano apresente um desempenho mais satisfatório. As demarcações transversais apresentaram o melhor desempenho devido ao já citado efeito canalizado do tráfego que só desgasta pontos específicos da linha deixando os demais quase intactos. 
Avaliação retrorrefletiva de pintura de demarcação horizontal: peculiaridades ...

Tabela 4. Retrorrefletômetros diferentes com a mesma geometria (30m)

\begin{tabular}{|c|c|c|c|c|c|c|c|c|c|c|c|}
\hline \multicolumn{4}{|c|}{ km 282} & \multicolumn{4}{|c|}{ km 284} & \multicolumn{4}{|c|}{$\mathrm{km} 286$} \\
\hline \multicolumn{2}{|c|}{ Bordo } & \multicolumn{2}{|l|}{ Eixo } & \multicolumn{2}{|c|}{ Bordo } & \multicolumn{2}{|c|}{ Eixo } & \multicolumn{2}{|c|}{ Bordo } & \multicolumn{2}{|c|}{ Eixo } \\
\hline B & A & B & A & B & A & B & A & B & A & B & A \\
\hline$R L(30)$ & $R L(30)$ & $R L(30)$ & $R L(30)$ & $R L(30)$ & $R L(30)$ & $R L(30)$ & $R L(30)$ & $R L(30)$ & $R L(30)$ & $R L(30)$ & $R L(30)$ \\
\hline 33 & 37 & 42 & 63 & 39 & 48 & 22 & 39 & 39 & 45 & 32 & 41 \\
\hline 34 & 44 & 46 & 63 & 35 & 49 & 34 & 43 & 40 & 44 & 33 & 43 \\
\hline 31 & 43 & 25 & 61 & 55 & 47 & 31 & 44 & 37 & 42 & 31 & 49 \\
\hline 36 & 40 & 42 & 37 & 33 & 50 & 30 & 38 & 30 & 37 & 33 & 43 \\
\hline 38 & 36 & 36 & 52 & 38 & 43 & 30 & 44 & 35 & 42 & 35 & 50 \\
\hline 36 & 48 & 35 & 42 & 36 & 62 & 29 & 40 & 33 & 45 & 37 & 47 \\
\hline 37 & 38 & 41 & 47 & 35 & 42 & 27 & 36 & 38 & 39 & 33 & 44 \\
\hline 34 & 42 & 27 & 37 & 31 & 40 & 29 & 44 & 33 & 40 & 31 & 44 \\
\hline 28 & 46 & 47 & 38 & 37 & 42 & 28 & 43 & 27 & 35 & 35 & 46 \\
\hline 35 & 41 & 40 & 54 & 36 & 38 & 30 & 40 & 32 & 39 & 31 & 42 \\
\hline
\end{tabular}

Demarcação
EIXO
BORDO
GERAL

Média FCRB/A
0,75
0,83
$\mathbf{0 , 7 9}$

Desvio-padrão
0,15
0,12
$\mathbf{0 , 1 4}$

Coeficiente de Variação

(\%)

19,5

14,7

17,7

Tabela 5. Comparação dos índices de retrorrefletividade mínimos normativos vs. desempenho obtido após 2 anos

\begin{tabular}{|c|c|c|c|c|c|c|c|c|}
\hline Referência & Geom. (m) & Branca & Amarela & $U L^{*}$ & UT TERM & UT ACRI & $R O D_{\text {bordo }}$ & $R_{\text {eixo }}$ \\
\hline DNIT & 15 & 100 & 80 & 111,4 & 228,2 & 85,9 & 69,5 & 73,3 \\
\hline ARTESP & 15 & 120 & 120 & 111,4 & 228,2 & 85,9 & 69,5 & 73,3 \\
\hline ANTT & 15 & 130 & 130 & 111,4 & 228,2 & 85,9 & 69,5 & 73,3 \\
\hline FHWA $(\mathrm{V} \leq 70)$ & 30 & 85 & 55 & 60,2 & 133,3 & 42,6 & NA & NA \\
\hline FHWA $(80 \leq \mathrm{V} \leq 90)$ & 30 & 100 & 65 & NA & NA & NA & 42,8 & 45,1 \\
\hline EN-1436 Chuvoso & 30 & 35 & 35 & 60,2 & 133,3 & 42,6 & 42,8 & 45,1 \\
\hline EN-1436 Seco & 30 & 100 & 100 & 60,2 & 133,3 & 42,6 & 42,8 & 45,1 \\
\hline Gibbons et al. (2013) & 30 & 150 & 150 & 60,2 & 133,3 & 42,6 & 42,8 & 45,1 \\
\hline Deballion et al. (2008) $(\mathrm{V} \geq 70)$ & 30 & 90 & 90 & NA & NA & NA & 42,8 & 45,1 \\
\hline Deballion et al. (2008) $(\mathrm{V} \leq 50)$ & 30 & 40 & 40 & 60,2 & 133,3 & 42,6 & NA & NA \\
\hline Hummer et al.(2011) & 30 & 100 & 65 & 60,2 & 133,3 & 42,6 & 42,8 & 45,1 \\
\hline
\end{tabular}

*Média das LMS2, LCO e LBO para as respectivas geometrias (15m e 30m)

$N A=$ Não se aplica

Outro aspecto interessante é a disparidade dos requisitos mínimos de retrorrefletividade das agências rodoviárias nacionais em relação às internacionais. Como as normas brasileiras (ABNT, 2005 e 2013) de levantamentos de retrorrefletividade recomendam um retrorrefletômetro de geometria $15 \mathrm{~m}$, os valores exigidos pelas agências ficam muito abaixo do que é comum para rodovias nos EUA e na Europa; aplicando o FCG nos requisitos mínimos do DNIT (2013) e da ARTESP (2014) chega-se a valores de retrorrefletividade na geometria de $30 \mathrm{~m}$ de 50 e $60 \mathrm{mcd} / \mathrm{m}^{2} / \mathrm{lux}$, respectivamente.

Para alcançar os valores referenciais mínimos americanos para as cores branca (100 mcd/m²/lux) e amarela (65 $\mathrm{mcd} / \mathrm{m}^{2} / \mathrm{lux}$ ), os requisitos últimos das agências brasileiras deveriam ser elevados na geometria de $15 \mathrm{~m}$ para 205 e 133 $\mathrm{mcd} / \mathrm{m}^{2} / \mathrm{lux}$, respectivamente. Não diferenciando a coloração da marca, os valores não deveriam ser menores que 205 $\mathrm{mcd} / \mathrm{m}^{2} / \mathrm{lux}$.

Se tais recomendações fossem adotadas, a durabilidade da sinalização em ambiente rodoviário seria de apenas três meses conforme mostram os valores da Tabela 3. Nos trechos urbanos (Tabelas 1 e 2), somente a transversal com termoplástico estaria de acordo com os requisitos mínimos de retrorrefletividade para os dois anos, a longitudinal com termoplástico e a transversal acrílica atingiriam o limite mínimo em 500 dias (16,6 meses) e 400 dias (13,3 meses), respectivamente.

No entanto, cabe salientar, que o material termoplástico é recomendado para pintura de demarcações viárias cuja vida útil deveria ser de três anos, segundo o Sistema de Custos Rodoviários do DNIT. Considerando a evolução do declínio de desempenho das pinturas longitudinais com termoplástico, é muito possível que, após três anos, nem mesmo as pinturas termoplásticas fiquem dentro dos limites estabelecidos nacionalmente, uma vez que já não atendem aos quesitos mínimos internacionais.

Estes aspectos finais deflagram a necessidade premente de uma profunda rediscussão das normas (mais especificamente da geometria adotada) ou dos patamares mínimos de retrorrefletividade a fim da sinalização horizontal no Brasil ter maior capacidade de garantir a efetivia segurança viária. Isto ocorre porque avalia-se, no país, a retrorrefletividade horizontal a partir de geometria de $15 \mathrm{~m}$, pouco conservadora se comparada com àquelas estabelecidas pelos Estados Unidos e Europa, e mantém os valores últimos similares aos empregados em países mais desenvolvidos. 


\section{CONCLUSÕES}

A sinalização horizontal de dois trechos urbanos e de um rodoviário foi analisada por meio de levantamentos de retrorrefletividade. Os resultados, após dois anos, indicaram um melhor desempenho das demarcações com material termoplástico em função desse material prover ancoragem às microesferas de maneira mais eficaz do que a tinta acrílica. Para os termoplásticos, variações de retrorrefletividade inicial foram fruto do arrancamento do drop-on e o posterior aparecimento do intermix com o desgaste da demarcação.

Algumas variações também ocorreram após o período inicial; a precipitação aliada ao efeito abrasivo do tráfego até três dias antes do levantamento aumentou a retrorrefletividade; a simulação do efeito de limpeza corroborou esta observação. $\mathrm{O}$ depósito de sujeira em demarcações de bordo no trecho urbano foi tão prejudicial à retrorrefletividade quanto o efeito abrasivo de veículos pesados e lentos no mesmo segmento. As marcas transversais urbanas apresentaram retrorrefletividade superior em relação às longitudinais. Apesar de o tráfego ser o mesmo, nas transversais ele é mais canalizado, desgastando somente a demarcação na trilha de roda e deixando os pontos próximos à borda praticamente intactos.

No trecho rodoviário, não obstante os valores iniciais apontarem uma retrorrefletividade maior para a coloração branca (bordo) em relação à amarela (eixo), a passagem dos veículos sobre o eixo, juntamente com o efeito da água da chuva, limpando-a de maneira mais efetiva, fez com que essa demarcação de eixo apresentasse retrorrefletividade levemente superior ao do bordo (que não recebeu significativa ação de limpeza do tráfego), invertendo a relação inicial ao final de dois anos. O desempenho da retrorrefletividade, portanto, é função não somente do tipo de material, mas também da posição da demarcação e das características do tráfego. Apesar de intuitiva, esta observação pode ser criteriosamente aferida neste estudo.

A avaliação final das demarcações frente aos requisitos mínimos internacionais mostrou o fraco desempenho dos materiais utilizados; o trecho rodoviário foi reprovado em quase todas as referências. Além disso, o fator de conversão entre geometrias revela que os requisitos mínimos aplicados por agências rodoviárias nacionais são, em média, a metade do que é considerado apropriado internacionalmente. Se tais requisitos fossem corrigidos perante recomendações internacionais, a sinalização rodoviária teria sua vida útil estimada em apenas três meses e a sinalização urbana em pouco mais de um ano.

Perante tais resultados, sugere-se uma revisão dos requisitos mínimos de retrorrefletividade nacionais e/ou a adoção de retrorrefletômetros de geometria $30 \mathrm{~m}$ para os levantamentos. Abre-se, também, espaço para uma ampliação da discussão sobre a qualidade dos materiais utilizados no Brasil e de processos de conservação das pinturas de demarcação viária, pouco discutidos na literatura técnica.

\section{REFERÊNCIAS}

Associação Brasileira de Normas Técnicas - ABNT (2005). NBR 14723: Sinalização Horizontal Viária - Avaliação da Retrorrefletividade. Rio de Janeiro, RJ: ABNT.
Associação Brasileira de Normas Técnicas - ABNT (2013). NBR 14723: Sinalização Horizontal Viária - Avaliação da Retrorrefletividade utilizando equipamento manual com geometria de $15 \mathrm{~m}$. Rio de Janeiro, RJ: ABNT.

Agência Nacional de Transportes Terrestres. Concessões Rodoviárias. Brasília, DF: ANTT. Disponível em:

$<$ http://www.antt.gov.br/index.php/content/view/5261/Concessoe s_Rodoviarias.html>. Acesso em: 12 dez. 2014.

ARTESP (2014) - Agência de Transportes do Estado de São Paulo [mensagem pessoal]. Mensagem recebida por <lucio.salles@usp.br> em 27 nov. 2014.

ASTM (2011) E 1710-11: standard test method for measurement of retroreflective pavement markings materials with CENprescribed geometry using a portable retroreflectometer. American Society for Testing and Materials, West Conshohocken, PA, USA.

DNIT (2010) Anuário Estatístico das Rodovias Federais 2010. Brasília.

DNIT (2013) RDC Presencial No 334/2013-00. Brasília, DF: Ministério dos Transportes.

Bahar, G.; Mollet, C.; Persaud, B.; Lyon, C.; Smiley, A.; Smahel, T.; McGee, H. (2004) NCHRP Report 518: Safety Evaluation of Permanent Raised Pavement Markers. Transportation Research Board of the National Academies, Washington, D.C.

Carlson, P. J.; Park, E. S.; Kang, D. H. (2013) Investigation of longitudinal pavement marking retroreflectivity and safety. Transportation Research Record, n. 2337, p. 59 - 66. DOI: 10.3141/2337-08

CNT (2012) Pesquisa CNT de Rodovias 2012: Relatório Gerencial. Brasília.

CNT (2014) Pesquisa CNT de Rodovias 2014: Relatório Gerencial. Brasília.

Debaillon, C.; Carlson, P. J.; Hawkins, G. H.; He, Y.; Schnell, T; Aktan, F. (2008) Review and development of recommended minimum pavement marking retroreflectivity levels. Transportation Research Record, n. 2055, p. 71 - 77. DOI: 10.3141/2055-09

Donnell, E. T.; Karwa, V.; Sathyanarayanan, S. (2009) Analysis of effects of pavement marking retroreflectivity on traffic crash frequency on highways in North Carolina. Transportation Research Record, n. 2103, p. 50 - 60. DOI: 10.3141/2103-07

European Committee for Standardization (ECS) (1999). Road marking materials - road marking performance for road users. EN 1436, Brussels.

FHWA (2008) Preliminary Economics Impacts of Implementing Minimum Levels of Pavement Marking Retroreflectivity. U.S. Department of Transportation, Federal Highway Administration, Office of Savety, Washington DC.

Gibbons, R. B.; Hankey, J. (2007) Wet night visibility of pavement markings: dynamic experiment. Transportation Research Record, n. 2015, p. 73 - 80. DOI: 10.3141/2015-09

Gibbons, R. B.; Williams, B.; Cottrell, B. (2013) Assessment of durability of wet night visible pavement markings. Transportation Research Record, n. 2337, p. 67 - 73. DOI: 10.3141/2337-09 
Graham, J. R.; King, L. E. (1991) Retroreflectivity Requirements for Pavement Markings. Transportation Research Record, n. 1316, p. 18-23.

Horberry, T.; Anderson, J.; Regan, M. A. (2006) The possible safety benefits of enhanced road markings: a driving simulator evaluation. Transportation Research Part F. n. 9, p. 77 - 87. DOI: 10.1016/j.trf.2005.09.002

Hummer, J. E.; Rasdorf, W.; Zhang, G. (2011) Linear mixedeffects models for paint-marking retroreflectivity data. Journal of Transportation Engineering, v. 137, n. 10, p. 705 - 716. DOI: 10.1061/(ASCE)TE.1943-5436.0000283

Lee, D.; Donnell, E. T. (2007) Analysis of pavement marking effects in nighttime driver behavior using fuzzy inference system. Journal of Computing in Civil Engineering, v. 21, n. 3, p. 200 - 210. DOI: 10.1061/(ASCE)0887-3801(2007)21:3(200)

Lundkvist, S. O.; Isacsson, U. (2007) Prediction of road marking performance. Journal of Transportation Engineering, v. 133, n. 6, p. $341-346$.

DOI: 10.1061/(ASCE)0733-947X(2007)133:6(341)

Migletz, J.; Graham, J. L.; Bauer, K. M.; Harwood, D. W. (1999)

Field Surveys of Pavement-Marking Retroreflectivity.

Transportation Research Record, n. 1657, p. 71-78. DOI: 10.3141/1657-10

Moreira, H.; Menegon, R. (2003) Sinalização Horizontal. Master Set Gráfica. São Paulo.

Mull, D. M.; Sitzabee, W. E. (2012) Paint pavement marking performance prediction model. Journal of Transportation Engineering, v. 138, n. 5, p. 618 - 624. DOI: 10.1061/(ASCE)TE.1943-5436.0000360

Ozelim, L.; Turochy, R. E. (2014) Modeling retroreflectivity performance of thermoplastic pavement markings in Alabama. Journal of Transportation Engineering, v. 140, n. 6, p. 1 - 6. DOI: $10.1061 /(A S C E) T E .1943-5436.0000661$

Parker, N. A.; Meja, M. S. J. (2003) Evaluation of the Performance of Permanent Pavement Markings. Transportation Research Record, n. 1824, p. 123-132. DOI: 10.3141/1824-14

Smadi, O.; Souleyrette, R. R.; Ormand, D. J.; Hawkins, N. (2008) Pavement marking retroreflectivity: analysis of safety effectiveness. Transportation Research Record, n. 2056, p. 17 24. DOI: $10.3141 / 2056-03$

Schwab, M. S. F. (1999) Estudo do desempenho dos materiais de demarcação viária retrorrefletivos. Dissertação (Pós-Graduação em Engenharia de Materiais) - Universidade Federal de Ouro Preto.

Zhang, G. (2009) Performance Analysis and Strategic Management of Longitudinal Pavement Markings. Thesis. Graduate Faculty of North Carolina State University, North Carolina.

Zwahlen, H. T.; Schnell, T. (1999) Visibility of Road Markings as a Function of Age, Retroreflectivity Under Low-Beam and High-Beam Illumination at Night. Transportation Research Record, n. 1692, p. 152-163. DOI: 10.3141/1692-16 